УДК $80 / 83$

DOI: 10.6060/BHIISUCT2020_85

\title{
Иванова Н.К.
}

Иванова Наталья Кирилловна - д.ф.н., профессор, заведующий кафедрой иностранных языков и лингвистики, ФГБОУ ВО «Ивановский государственный химикотехнологический университет», E-mail: ivanova@isuct.ru

\section{АНГЛИЙСКИЙ ЯЗЫК В РОССИЙСКОЙ НАУЧНОЙ СРЕДЕ: ОСНОВНЫЕ ТЕНДЕНЦИИ И ОСОБЕННОСТИ ФУНКЦИОНИРОВАНИЯ И ВОСПРИЯТИЯ}

Посвящается 90-летию ИХТИ-ИГХТА-ИГХТУ

\begin{abstract}
В статье рассматриваются актуальные проблемы, связанные с распространением и восприятием среди ученых России английского языка как средства международного научного общения, а также обсуждаются вопросы, связанные с организацией обучения этому основному в настоящее время языку науки. Содержание статьи основано на материале имеющихся статистических данных, проведенных автором опросов и собственного многолетнего опыта преподавания английского языка для научной коммуникации магистрантам и аспирантам. Особое внимание уделяется сочиолингвистическим характеристикам владения иностранным языком и уровням компетентности в различных видах речевой деятельности.
\end{abstract}

Ключевые слова: английский как язык международного научного общения, роль англоязычных публикаций в научной карьере, личном и вузовском рейтинге, межъязыковая конкуренция, перспективы ее развития.

\section{Ivanova N.K.}

Ivanova Natalya Kirillovna - Doctor of Philology, Professor, Ivanovo State University of Chemistry and Technology, Head of the Department of Foreign Languages and Linguistics. E-mail: ivanova@isuct.ru

\section{THE ENGLISH LANGUAGE IN RUSSIAN ACADEMIC ENVIRONMENT: BASIC TRENDS AND FEATURES OF FUNCTIONING AND PERCEPTION}

The paper discusses some current issues related to the dissemination and perception of English among Russian academe as a medium of international scholarly communication. The content of the paper is based on the available statistical data and the author's experience of teaching English for academic communication to postgraduates and master students. Particular attention is paid to the sociolinguistic character- 
istics of a foreign language proficiency and levels of competence characteristic for students and lecturers in various types of speech activity.

Key words: English as the language of international academic communication, the role of English-language publications in the academic career, personal and university ranking, interlanguage competition, prospects for its development.

\section{ВВЕДЕНИЕ}

В настоящее время совершенно очевидно, что английский язык стал подлинным языком международной коммуникации, реальным средством общения представителей различных стран мира, носителей разных национальных языков. По этой причине в лингвистике появились термины International English, English as Lingua Franca и др., а разновидности вариантов английского языка получили название World Englishes, указывающее, прежде всего, на новое качество иностранного языка, модифицированное под воздействием родного языка и культуры, ориентацию на так называемые эндонормы [16, 21]. Некоторые территориально-национальные разновидности английского языка иногда называют «корейский английский», «китайский английский», «восточноевропейский английский», «русский английский» и т.д. Особенностям изучения и функционирования последнего в российской научной коммуникации и будет посвящена данная статья. Однако следует заметить, что, как и другие разновидности английского языка, «русский английский» имеет несколько функциональных зон, традиционно выделяемых в социолингвистике: акролект, мезолект и базилект [19, p. 27]. 3.Г. Прошина, исходя из их социолингвистических характеристик, выделяет: Russia English (английский язык образованных людей, дипломатических документов, дикторов иноязычных СМИ и т.д.), Russian English (английский язык большей части российских ученых, ряда преподавателей английского языка, некоторых «продвинутых» (advanced) выпускников вуза и т.д.) и Runglish (Renglish) - английский язык студентов и школьников, изучающих его на протяжении нескольких лет, но вне языкового окружения, так называемый learner English. Последняя из указанных разновидностей не только хорошо известна всем преподавателям иностранного языка в России, но и достаточно подробно описана с лингвистической точки зрения $[12,17,19]$. В этих и других работах проанализированы типичные лексико-грамматические ошибки, фонетические особенности английской речи русских, вызванные интерференцией родного и иностранного языков.

В мезолектной зоне, как полагают лингвисты, на всех уровнях (фонетическом, лексическом, грамматическом, стилистическом) также проявляются особенности реализации «чужого» языка. Однако современные исследования показывают, что они не всегда являются ошибками, далеко не всегда затрудняют процесс коммуникации (см., например, результаты проекта VOICE [21]), и поэтому они рассматриваются как лингвистические отклонения (девиации) и инновации. Примером таких отклонений от лексико-семантических норм английского языка могут служить: неразличение в устной и письменной научной коммуникации слов magazine/journal; scientist/scholar; question/problem/issue; thesis/dissertation; academic/scientific/research, etc., а также такие буквализмы, как Doctor of Pedagogical Sciences, Culturology, theses (в значении «тезисы»), technical вместо engineering и др.

\section{АНГЛИЙСКИЙ ЯЗЫК В РОССИИ: ОПЫТ ПРОШЛОГО И ТЕНДЕНЦИИ СОВРЕМЕННОГО ФУНКЦИОНИРОВАНИЯ}

Области распространения английского языка в современной России постоянно расширяются. Кроме сферы образования и науки, политики и экономики, это реклама, 
музыка, компьютерные игры, виртуальная коммуникация и т.д. Для того чтобы полнее проанализировать текущую ситуацию с использованием английского языка в современном образовательном и научном дискурсе, обратимся вначале к некоторым историческим фактам и важным лингвистическим реалиям, сложившимся за многие годы обязательного изучения английского языка как учебной дисциплины.

Английский язык вошел в России в моду вместе с великой английской литературой в начале XIX века. В тот период его изучали в основном самостоятельно или с помощью гувернеров, а в учебных заведениях он преподавался редко. На протяжении долгих лет основными иностранными языками в российском, а затем в советском обществе были французский (см. об особенностях билингвизма в России XIX века [7]) и немецкий. Только после Великой Отечественной войны 1941-1945 гг. иностранный язык становится обязательной частью школьной программы, и лишь в послевоенные 50-е годы английский язык стали преподавать (наряду с немецким или французским) в высших учебных заведениях, например, будущим инженерам. Как пишет А.В. Павловская, «иностранные языки тоненькой нитью связывали советских людей с внешним миром, давали ощущение причастности к общему мировому процессу» $[10$, c. 210$]$.

Примечательно, что с самого начала распространения английского языка в СССР за основу обучения был выбран британский языковой стандарт, который преподавался в университетах и педагогических институтах будущим учителям и преподавателям этой дисциплины. После распада Советского Союза в новых социальнополитических и экономических условиях на авансцену вышел американский английский с его языковыми правилами и моделями. Это привело к очень своеобразной ситуации: во-первых, к нередкому смешению двух норм в устной и письменной речи, в том числе - в научной коммуникации, во-вторых, к генеративной ориентации. Так, традиционного британского варианта с его орфографией, грамматикой, произношением, словоупотреблением придерживаются представители старшего поколения. Для более молодого поколения стало предпочтительнее ориентироваться (обычно, весьма бессистемно) на американский английский с упрощенным написанием, особым произношением (ср.: program, color, sulfide, license n.,v., disk, schedule / ‘kedju:1/, etc.), грамматическими и лексическими нормами и т.д. Согласно сложившейся традиции, эти две модели по-разному воспринимаются русскими пользователями: британской модели придается бОльшая эстетическая ценность, а американский английский рассматривается как вариант практический, эффективное средство коммуникации [19, р. 29].

Английский язык в России, как отмечалось выше, характеризуется большой вариативностью в разных социолектах и идиолектах, причем, принадлежа к экзонормативной разновидности, он, однако, имеет некоторые характеристики, совпадающие с «английскими языками» (World Englishes) «внешнего» и «расширяющегося» круга Б. Качру [14].

Несмотря на широкое распространение английского языка в российском обществе, его функции не так многочисленны, как в по-настоящему билингвальных или мультилингвальных сообществах, и его главная функция - использование в качестве средства межнационального общения, межкультурной коммуникации. Важное место при этом занимает письменная или устная научная коммуникация, при которой английской язык выступает как средство обмена научными достижениями через англоязычные публикации в научной периодике и выступления на конференциях. Для российских ученых важной является функция межличностного общения для установления неформальной коммуникации с иностранными коллегами со всего мира - реального (на конференциях) или виртуального (в чатах, на форумах, в профессиональных блогах и т.д.). 


\section{РОЛЬ АНГЛИЙСКОГО ЯЗЫКА В ИНТЕРНАЦИОНАЛИЗАЦИИ РОССИЙСКОГО ОБРАЗОВАНИЯ}

В современной России именно с английским связывают надежды на интернационализацию российского образования. С этой целью в наших вузах вводятся учебные курсы на английском языке, выпускникам выдаются дипломы Европейского образца, осуществляются политика продвижения наших высших учебных заведений за рубежом для привлечения иностранных студентов, а также активно открываются Центры академического письма для обучения студентов и НПР языковым правилам подготовки англоязычных публикаций [1], а рубрика «Академическое письмо» стала постоянной в журнале «Высшее образование в России».

Новые российские реалии после распада СССР в 1991 г. (см. детальный обзор ситуации в советской науке [19, р. 149-160]) обусловили новые возможности и перспективы международного общения наших ученых с зарубежными коллегами, что в свою очередь привело к новому пониманию роли английского языка, к стремлению его изучить самостоятельно или на специальных курсах, чтобы представлять результаты своих исследований международной научной общественности не на родном языке, а на иностранном. К сожалению, до сих пор немногие российские ученые владеют западноевропейским научным стилем, несмотря на вызовы времени [3, 22]. Напомним, что саксонский академический интеллектуальный стиль, характерный для англоязычных публикаций, определяет и англо-американские стандарты письменного изложения. Они предполагают строгую логико-смысловую структуру с четким членением статьи, тематическую прогрессию, эмпиризм, выведение гипотез индуктивным путем. Русский научный стиль, как известно, является тевтонским по своим характеристикам: с акцентом на теоретические положения, дедуктивным стилем аргументации, большим количеством ссылок на общепринятые в данной науке авторитеты вместо собственных эмпирических данными [3; 4, с. 24-25].

Интенсивное международное научное сотрудничество последних лет способствовало, на наш взгляд, овладению русскими учеными эксплицитной логико-смысловой структурой (это требование в настоящее время распространяется и на русскоязычные публикации в авторитетных журналах) для обеспечения институциональных и международных научных конвенций. Однако продуцированные ими тексты на английском языке часто не имеют необходимых элементов когезии: стандартных клише для перехода от одной логической части к другой, маркеров содержательного структурирования дискурса, необходимых фреймовых конструкций и пр. Несомненно, что это также должно стать содержанием курса «Англоязычная научная коммуникация», введенного в ряде вузов страны, в том числе в ИГХТУ.

Заметим, что иностранный язык не был забыт в Программе модернизации российского высшего образования. Так, например, с 2011 г. появилась государственная программа повышения публикационной активности российских ученых в зарубежных журналах с высоким импакт-фактором и введен соответствующий критерий в мониторинге научной деятельности вузов. Ради последнего многие ведущие российские университеты ввели систему материального поощрения ученых, публикующих статьи на английском языке в высокорейтинговых журналах, входящих в международные наукометрические базы Scopus и Web of Science, стали учитывать эти публикации в рейтинге эффективной работы преподавателя. Публикация достижений научноисследовательской деятельности ведущих российских ученых предусматривается как в Постановлении Правительства РФ № 218, так и в проекте 5-100.

Закономерен вопрос: был ли готов многотысячный контингент преподавателей и научных сотрудников вузов к коммуникации на иностранном языке? Справедливо замечание И.Б.Короткиной, что «рост популярности академического письма в России 
еще не означает институциональной готовности высшего образования» к пересмотру традиционных программ обучения будущих исследователей, введению специальных курсов и «специализированных подразделений академического письма в своей системе» $[8$, c. 76$]$.

\section{ФУНКЦИОНАЛЬНАЯ НАГРУЗКА АНГЛИЙСКОГО ЯЗЫКА В НАУЧНО- ПРОФЕССИОНАЛЬНОЙ ДЕЯТЕЛЬНОСТИ ПРЕПОДАВАТЕЛЕЙ ВУЗА}

Обратимся к имеющимся статистическим данным. В 2011 г. был проведен опрос среди 461 преподавателя 20 ведущих российских национальных, научноисследовательских, крупных федеральных университетов (Москвы, Санкт-Петербурга, Архангельска, Казани, Томска, Новосибирска, Нижнего Новгорода, Владивостока, Якутска и др.). Опрошенные работали в разных отраслях науки (50\% - в области естественных наук, 38 \% - общественных и гуманитарных, $9 \%$ - в прикладных, $2 \%$ в педагогических). В ходе этого опроса определялась роль английского языка (АЯ) в их научно-исследовательской и преподавательской деятельности и его основные функции. Так, было установлено, что 86 \% опрошенных использовали английский язык в научной коммуникации, а $14 \%$ - нет [19, p. 157]. Казалось бы, все хорошо: российское научное общение постепенно становится двуязычным, однако приведенные в этом исследовании данные о функциональности АЯ заставляют поменять свое мнение. Как видно из приведенной Таблицы 1 (перевод мой - Н.И.), по-прежнему (88 \%) основная функция, как и в начале 2000-х [15], - чтение англоязычных профессиональных журналов. Далее (59 \%), как примета времени, следует оформление документов на гранты и программы. Было установлено, что $48 \%$ опрошенных участвовали в международных научных проектах, например, в научных конференциях с докладом на английском языке, a $21 \%$ опрошенных использовали английский язык в преподавательской деятельности. По данным анализируемого опроса, 65 \% респондентов имели публикации на русском и на английском языках, а $3 \%$ являлись авторами публикаций только на английском языке.

Таблица 1

Функциональная нагрузка английского языка в научно-профессиональной деятельности преподавателей вуза (данные 2011 г.) [19]

\begin{tabular}{|l|c|c|}
\hline \multicolumn{1}{|c|}{ Функция английского языка } & \% (n= число ответов) & Ранг функции \\
\hline Чтение профессиональной литературы & $88 \%(\mathrm{n}=397)$ & 1 \\
\hline Оформление и выполнение грантов & $59 \%(\mathrm{n}=265)$ & 2 \\
\hline Участие в международных проектах & $48 \%(\mathrm{n}=215)$ & 3 \\
\hline Преподавательская деятельность & $21 \%(\mathrm{n}=83)$ & 4 \\
\hline $\begin{array}{l}\text { Общение с (зарубежными? - Н.И.) университет- } \\
\text { скими коллегами }\end{array}$ & $13 \%(\mathrm{n}=57)$ & 5 \\
\hline Общее число респондентов & $\mathbf{4 5 0}$ & \\
\hline
\end{tabular}

Опрос показал наличие у преподавателей личной (карьерный рост) и общественной (рейтинг кафедры, лаборатории, вуза) мотивации к изучению и применению английского языка, но не слишком активное его использование в разных сферах научной деятельности ученых и преподавателей ведущих вузов страны.

На наш взгляд, большой интерес представляют данные Таблицы 2, в которой, также на основе исследования Е. Лорик [19], содержится информация об ощущаемой важности английского языка для успешной научной карьеры. Значимость АЯ оценивалась по шкале Ликарта: «очень значимо» (О3), «достаточно значимо (ДЗ), «малозначиMO» (M). 
Результаты оценки значимости АЯ по шкале Ликарта

Таблица 2

\begin{tabular}{|c|c|}
\hline Виды активности & Оценка: О3 Д3 М \\
\hline $\begin{array}{l}\text { Научная публикация в англоязычном между- } \\
\text { народном журнале }\end{array}$ & $73 \%(324) 19 \%(85) 8 \%(35)$ \\
\hline $\begin{array}{l}\text { Научная публикация в русскоязычном журна- } \\
\text { ле из списка ВАК }\end{array}$ & $57 \%$ (257) $38 \%(172) 4 \%$ 919) \\
\hline $\begin{array}{l}\text { Выступление на английском языке на между- } \\
\text { народной конференции }\end{array}$ & $51(220) 41 \%$ (175) $8 \%$ (34) \\
\hline Учебное пособие на русском языке & $19 \%(75) 43 \%(170) 38 \%(152)$ \\
\hline $\begin{array}{l}\text { Выступление на национальной или регио- } \\
\text { нальной конференции на русском языке }\end{array}$ & $7 \%$ (27) $62 \%$ (254) $31 \%$ (128) \\
\hline $\begin{array}{l}\text { Выступление на вузовской конференции на } \\
\text { русском языке. }\end{array}$ & $5 \%$ (19) $27 \%$ 9113) $68 \%$ (282) \\
\hline Общее число ответивших & 448 \\
\hline
\end{tabular}

Как показывают данные анализируемого опроса, среди преподавателей ведущих университетов России уже несколько лет тому назад четко обозначилась тенденция к конкуренции между языками науки - русским и английским и к их распределению по видам учебной, методической и научной деятельности преподавателей, а также к осознанию значимости публикации и презентации результатов исследования на английском языке как более важного и престижного научного и карьерного «капитала». При этом, как указывают приведенные цифры, на русском языке не потеряли значимости только публикации в журналах из списка ВАК. Обратим также внимание, что более важное значение придается печатной публикации на английском языке, чем устному выступлению, то есть «опосредованной научной коммуникации». В ее подготовке обычно, кроме самого автора (авторов), принимают участие переводчики-редакторы, рецензенты, нередко также указывающие на наличие стилистических отклонений и лексико-грамматических погрешностей. Нельзя не отметить, что за последние годы значительно изменился стиль и упростился язык англоязычных научных публикаций, что позволяет российским ученым, как нам известно, успешно компилировать содержание своих статей на английском языке на основе фраз, конструкций и пр. из оригинальных статей на английском языке. На наш взгляд, этот способ более эффективен и корректен, чем использование машинного перевода, который требует тщательного допереводного и постпереводного редактирования исходного и переведенного текста на основе знаний особенностей профессиональной терминологии и семантики общенаучной лексики.

Выступление с устным докладом на английском языке предполагает владение другим набором компетенций, связанных с корректным фонетическим оформлением выступления, аудированием и устной речью. Традиционно, к сожалению, обучение им в магистратуре и аспирантуре осуществляется «по остаточному принципу», и большая часть времени расходуется на повторение (в который раз?) грамматики, профессиональной лексики, на овладение навыками перевода. Таким образом, на наш взгляд, перед преподавателями английского языка в вузе стоит важная задача «перефокусировать» задачи обучения на другие виды речевой деятельности.

\section{КОНКУРЕНЦИЯ ЯЗЫКОВ НАУКИ: РУССКИЙ ИЛИ АНГЛИЙСКИЙ?}

Возникает закономерный вопрос: продолжится ли тенденция к неуклонному уменьшению роли русского языка как языка международной науки? Напомним, что по имеющимся статистическим данным в 1960-1980-е г.г. русский язык имел статус одно- 
го из главных языков науки (наряду с немецким, французским и английским) с пиком 20.48 \% в 1970-е годы [9;19] и занимал, например, в научных публикациях по химии, биологии, медицине второе место по распространенности после английского. После резкого уменьшения русскоязычных научных публикаций в 90-е годы и сокращения их доли до $2.5 \%$ к 2007 г. (по данным РАН - 1,43 статьи на одного ученого в 20032007 гг.) [19]. В настоящее время, несмотря на то, что роль английского языка в науке продолжает повышаться, в ряде научных направлений, например, социальногуманитарных, преобладает русский язык, до сих пор распространенное средство научной коммуникации в России и в ряде бывших республик СССР.

Русскоязычные журналы, как известно, также входят в международные аналитические базы, и в связи с этим они ориентируются не на национальные, а международные конвенции научных публикаций: обязательны «прозрачное» название, грамотная и исчерпывающая аннотация и тщательно подобранные ключевые слова. Так, за период 2006-2017 гг. в Web of Science было обнаружено «более 58 тыс. публикаций на русском языке, при этом треть из них вообще не имеет информации об аффилиации авторов». На Рис.1 представлено распределение публикаций по странам авторов, и эти статьи, как указывается, принадлежат «неидентифицированным» странам». Причем «за 10 лет количество таких публикаций уменьшилось в пять раз, что свидетельствует о значительном улучшении качества данных, представляемых в Web of Science русскоязычными изданиями преимущественно социогуманитарной направленности. Более половины этих авторов - из России, но в их создании участвовали соавторы более чем из 90 стран $[9 ; 13 ; 18]$. Данные публикации читаются и цитируются в основном российскими учеными (74\% цитирований приходят из России, $7 \%$ - из Китая, $5 \%$ - из США). Как показывает статистика, «с 2011 г. в Scopus количество научных направлений с публикациями на русском языке увеличилось более чем вдвое, как и взвешенное по научной области количество просмотров, однако число стран, цитирующих русскоязычные статьи, остаётся на стабильном уровне: 70-80». [9].

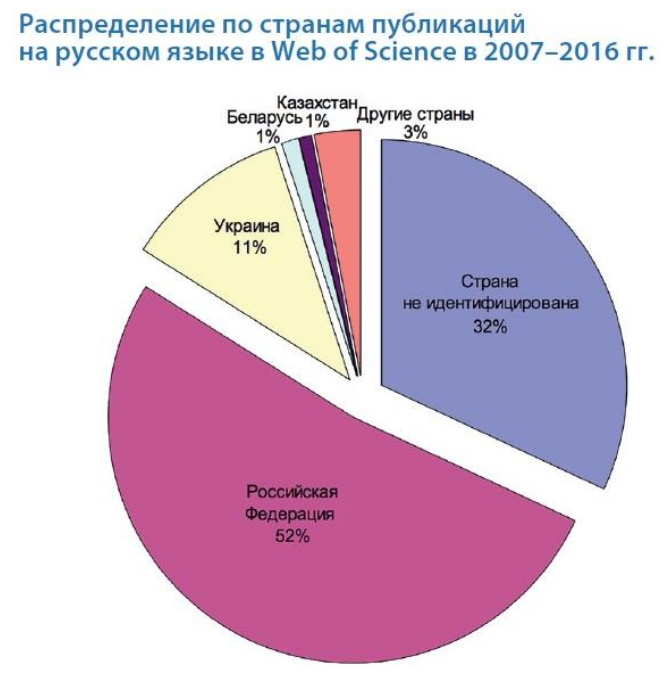

Рис. Распределение русскоязычных публикаций в журналах базы Web of Science в 2007-2016 гг. [9]

Таким образом, упомянутая ранее Программа модернизации Российской науки, предусматривающая систему грантов для российских ученых, создание различных фондов и программ сотрудничества, а в последние годы — активное включение ряда российских журналов в международные наукометрические базы, способствовали активизации научной деятельности и увеличению количества публикаций на английском 
языке. В современной России постепенно складывается «языковая конкуренция» между языками науки, но в обществе, как показали вышеприведенные данные анкетирования, сформировалось ощущение значимости и престижности английского языка для успешной научной карьеры.

\section{КАК ВОСТРЕБОВАНО ЗНАНИЕ АНГЛИЙСКОГО ЯЗЫКА: РЕЗУЛЬТАТЫ ОПРОСА ПРЕПОДАВАТЕЛЕЙ ИГХТУ И ИВГПУ}

В целом, на наш взгляд, можно говорить о наличии четкой корреляции между уровнем научных исследований, их активностью в конкретном университете (исследовательском, национальном, федеральном с научными школами, провинциальном многопрофильном и т.д.) и востребованностью знаний по иностранному языку для научной и преподавательской деятельности (см. результаты мониторинга продуктивности научной деятельности российских вузов по областям исследования в [11].

Приведем в качестве доказательства этого тезиса данные нашего опроса, проведенного в 2018 г. среди преподавателей различных кафедр двух ивановских вузов Ивановского государственного химико-технологического университета и Ивановского государственного политехнического университета [5]. Целью исследования было получение информации о языковой личности и речевом портрете представителей современной технической интеллигенции, преподавателей вуза. Часть вопросов касалась знания иностранного языка и потребности его применения в научной и преподавательской деятельности и для расширения «лингвистического кругозора».

Все респонденты, за очень редким исключением, были выпускниками этих же вузов, а возраст участников анкетирования варьировался от 30 до 70 лет, но возраст основной группы (44\%) составлял 30-45 лет. Доля преподавателей женщин (52\%) и мужчин (48\%) была приблизительно одинакова. Как и в нашем предыдущем исследовании [6], неожиданно мало было получено положительных ответов на вопрос, помогает ли иностранный язык в понимании современного русского словоупотребления. Вариант «частично» указали 35 \%, «нет» выбрали $40 \%$, «да» — только $25 \%$. По нашим данным, у большей части опрошенных преподавателей отсутствует корреляция между родным и иноязычным языковыми кодами, и знание иностранного языка не помогает им понимать современные англоязычные заимствования в русском языке, несмотря на регулярное чтение $80 \%$ преподавателей научной литературы на иностранном языке. Однако эта цифра усредненная, отдельно по вузам она следующая: ИГХТУ 52 \%, ИвГПУ $-28 \%$. Еще меньше (15\%) опрошенных указали, что они регулярно пишут статьи на иностранном языке. Вызывает также удивление тот факт, что в современных условиях, когда интернет предоставляет изобилие образовательных ресурсов для самостоятельного изучения иностранного языка, только $10 \%$ преподавателей технического вуза используют эти возможности для языкового самообразования.

\section{ЗАКЛЮЧЕНИЕ}

Проведенные нами опросы и наш опыт преподавания английского языка различным категориям учащихся показывают, что степень владения им различна и зависит не только от наличия или отсутствия мотивации к изучению языка и его применению в научной деятельности. В настоящее время можно отметить явные генеративные (поколенческие) характеристики: представители старшего поколения имеют более совершенные навыки письменной коммуникации на ИЯ, активно и корректно используют различные клише, свободно оперируют терминологией своей научной области, хорошо знают основные грамматические правила английского языка. Представители же молодого поколения, получившие образование в новых условиях и при новых возможностях самостоятельного изучения иностранного языка, лучше владеют устной речью: у них 
лучше произношение и более развиты навыки аудирования, больше запас формул речевой коммуникации. Лишь немногие из них, однако, становятся подлинными билингвами, переходят из зоны мезолекта к акролекту, поскольку для этого необходимы целенаправленные усилия по языковому самообразованию, сильная мотивация и особые условия коммуникации, например, научная стажировка за рубежом, интенсивное общение с коллегами на английском языке в чатах и профессиональных блогах. Это, на наш взгляд, требует как усилий со стороны Министерства образования и науки по организации возможностей международного научного сотрудничества, так и со стороны вузов для реформирования системы преподавания английского языка, изменения его прагматической направленности в зависимости от уровня и этапа изучения с учетом научнопрофессиональных потребностей в научной коммуникации. Это будет способствовать решению важных научных задач нашей страны: «стать пятой по числу публикаций в областях, считающихся приоритетными, а 500 журналам - войти в международные базы данных к 2024 г.» Работы 33 тысяч учёных должны индексироваться в первом и втором квартилях, «необходимо выпустить 200 статей по генетическим исследованиям» [2].

\section{ЛИТЕРАТУРА}

1. Базанова Е.М. Лаборатория научной коммуникации: российский опыт // Высшее образование в России. 2015. № 8-9. С. 135-143.

2. Бейлина Е. Российская наука и научная информация: парадоксы эволюции. // Университетская книга. URL: http://www.unkniga.ru/biblioteki/fonds/10166-rossiyskayanauka-i-nauchnaya-informatsiya-paradoksy-evolyutsii.htmlksah-tsitirvaniya-est-lishans.html (дата обращения: 21.02.2020 г.).

3. Ванхала-Анишевски М. Логико-смысловая структура русского научного текста в восприятии ее студентами-иностранцами // Вестник МГУ. Серия 19: Лингвистика и межкультурная коммуникация. 2000. № 4. С. 21-27.

4. Добрынина О.Л. Академическое письмо для публикационных целей: стилистические погрешности // Высшее образование в России. 2019. Т. 28. № 10. С. 38-49. DOI: https://doi.org/10/31992/0869-3617-2019028-10-38-49.

5. Иванова Н.К., Дельцова В.А. Вузовская интеллигенция г. Иваново: штрихи к портрету (по материалам анкетирования преподавателей технических вузов) // Социокультурное пространство Ивановского края: прошлое, настоящее, будущее. сб. науч. трудов. Иваново: ИвГУ, 2018. С. 231-240.

6. Иванова Н.К., Меркулова Н.Е. Русский и иностранный языки в языковом сознании вузовской технической интеллигенции// Лингвориторическая парадигма: теоретические и прикладные. 2017. № 22-1. С. 85-89.

7. Иванова Н.К., Меркулова Н.Е., Иностранные языки в структуре языковой личности Н.М. Карамзина (опыт лингво- и социокультурного анализа) // Известия вузов. Серия: Гуманитарные науки. 2016. № 7 (3). С. 196-203.

8. Короткина И.Б. Университетские центры академического письма в России: цели и перспективы // Высшее образование в России. 2016. № 1 (197). С. 75-86.

9. Москалева О.В., Акоев М.А. Публикации на разных языках в индексах цитирования, или есть ли шанс у русского языка в науке? // URL: http://www.unkniga.ru/kultura/8295publikatsii-na-raznyh-yazykah-v-inde (дата обращения: 21.02 .2020 г.).

10. Павловская А.В. Образование в России: история и традиции. М.: Олма-Пресс, 2003. $383 \mathrm{c}$.

11. Предметный рейтинг научной продуктивности вузов-2019. URL: http://www.acexpert.ru/analytics/ratings/predmetniy-reyting-nauchnoy-produktivnosti-vuzov--2.html (дата обращения: 29.02.2020 г.).

12. Савицкий В.М., Куровская А.Е. Национальная специфика английской речи (грамматический аспект). Москва: Pearson Education: Московский городской педагогический университет. 2004. 145 с. 
13. Carli A.,Ammon U. (eds). Linguistic Inequality in Scientific Communication Today //AILA Review . Vol. 20. Amsterdam and Philadelphia: John Benjamins. 2007. 137 p.

14. Kachru B.B. The alchemy of English: the spread, functions, and models of non-native Englishes. Oxford: Pergamon Press.1986. 200 p.

15. Kryochkova T. English as a Language of Science in Russia // The Dominance of English as a Language of Science: effect on other languages and language communities (ed. by Amman U.). Berlin and New York: Walter and Gruyter. 2001. P. 405-423.

16. McArthur T. The Oxford Guide to World English. Oxford University Press, 2003. 501 p.

17. Monk B., Burak A. 'Russian Speakers' // Learner English. A Teacher's Guide to Interference and other problems. Ed. by Swan M and Smith D ( ${ }^{\text {nd }}$ ed.).Cambridge University Press. 2001. P. $145-161$.

18. Montgomery S. L. Impacts of a Global Language on Science: Are There Disadvantages? [// Language as a Scientific Tool. Shaping Scientific Language Across Time and National Traditions. 2016. P. 199-218.

19. Russian English. History, Functions, and Features. / Ed. by Zoya G.Proshina and Anna A,Eddy. Cambridge University Press. 2016. 309 p.

20. Schneider Ed.W. English Around the World. Cambridge University Press, 2011. 280 p.

21. Seidlhofer B. Understanding English as a Lingua Franca. Oxford Applied Linguistics. Oxford University Press, 2013. P. 240.

22. Velichkovsky V.V. Open Access Publishing - a Challenge for Russian Psychology // Psychology Science Quarterly. 2009. № 51. P. 147-159.

\section{REFERENCES (TRANSLITERATED)}

1. Bazanova E.M. Laboratoriya nauchnoj kommunikacii: rossijskij opyt // Vysshee obrazovanie v Rossii. 2015. № 8-9. S. 135-143.

2. Bejlina E. Rossijskaya nauka i nauchnaya informaciya: paradoksy evolyucii. //Universitetskaya kniga. Elektronnyj resurs. Rezhim dostupa: http://www.unkniga.ru/biblioteki/fonds/10166-rossiyskaya-nauka-i-nauchnaya-informatsiyaparadoksy-evolyutsii.htmlksah-tsitirvaniya-est-li-shans.html. Data obrashcheniya 21 fevralya $2020 \mathrm{~g}$.

3. Vanhala-Anishevski M. Logiko-smyslovaya struktura russkogo nauchnogo teksta v vospriyatii ee studentami-inostrancami // Vestnik MGU. Seriya19: Lingvistika i mezhkul'turnaya kommunikaciya. 2000. № 4. Moskva: MGU S. 21-27.

4. Dobrynina O.L. Akademicheskoe pis'mo dlya publikacionnyh celej: stilisticheskie pogreshnosti // Vysshee obrazovanie v Rossii. 2019. T. 28. № 10. S. 38-49. DOI: https://doi.org/10/31992/0869-3617-2019028-10-38-49.

5. Ivanova N.K., Del'cova V.A. Vuzovskaya intelligenciya g. Ivanovo: shtrihi k portretu (po materialam anketirovaniya prepodavatelej tekhnicheskih vuzov) // Sociokul'turnoe prostranstvo Ivanovskogo kraya: proshloe, nastoyashchee, budushchee. Ivanovo: IvGU, 2018. S. 231-240.

6. Ivanova N.K., Merkulova N.E. Russkij i inostrannyj yazyki v yazykovom soznanii vuzovskoj tekhnicheskoj intelligencii// Lingvoritoricheskaya paradigma: teoreticheskie i prikladnye aspekty. 2017. № 22-1. S. 85-89.

7. Ivanova N.K., Merkulova N.E., Inostrannye yazyki $v$ strukture yazykovoj lichnosti N.M. Karamzina (opyt lingvo- i sociokul'turnogo analiza) // Izvestiya vuzov. Seriya «Gumanitarnye nauki». 2016. № 7 (3). S. 196-203.

8. Korotkina I.B. Universitetskie centry akademicheskogo pis'ma v Rossii: celi i perspektivy // Vysshee obrazovanie v Rossii. 2016. № 1 (197). S. 75-86.

9. Moskaleva O.V., Akoev M.A. Publikacii na raznyh yazykah v indeksah citirovaniya, ili est' li shans u russkogo yazyka v nauke? // Universitetskaya kniga. [Elektronnyj resurs]. Rezhim dostupa: : http://www.unkniga.ru/kultura/8295-publikatsii-na-raznyh-yazykah-v-inde. Data obrashcheniya 21 fevralya $2020 \mathrm{~g}$.

10. Pavlovskaya A.V. Obrazovanie v Rossii: istoriya i tradicii. M.:Olma-Press. 2003. 383 s. 
11. Predmetnyj rejting nauchnoj produktivnosti vuzov-2019. [Elektronnyj resurs]. Rezhim dostupa: $\quad$ http://www.acexpert.ru/analytics/ratings/predmetniy-reyting-nauchnoyproduktivnosti-vuzov---2.html. Data obrashcheniya 29 fevralya $2020 \mathrm{~g}$.

12. Savickij V.M., Kurovskaya A.E. Nacional'naya specifika anglijskoj rechi (grammaticheskij aspekt). Moskva:Pearson Education: Moskovskij gorodskoj pedagogicheskij universitet. 2004. $145 \mathrm{~s}$.

13. Carli A.,Ammon U. (eds). Linguistic Inequality in Scientific Communication Today //AILA Review . Vol. 20. Amsterdam and Philadelphia: John Benjamins. 2007. 137 p.

14. Kachru B.B. The alchemy of English: the spread, functions, and models of non-native Englishes. Oxford: Pergamon Press, 1986. 200 p.

15. Kryochkova T. English as a Language of Science in Russia // The Dominance of English as a Language of Science: effect on other languages and language communities (ed. by Amman U.). Berlin and New York: Walter and Gruyter. 2001. P. 405-423.

16. McArthur T. The Oxford Guide to World English. Oxford University Press, 2003. 501 p.

17. Monk B., Burak A. 'Russian Speakers' // Learner English. A Teacher's Guide to Interference and other problems. Ed. by Swan M and Smith D (2nd ed.).Cambridge University Press. 2001, P. 145-161.

18. Montgomery S.L. Impacts of a Global Language on Science: Are There Disadvantages? [// Language as a Scientific Tool. Shaping Scientific Language Across Time and National Traditions. 2016. P. 199-218. [Электронный ресурс] Режим доступа: https://doi.org/ $10.4324 / 9781315657257$.

19. Russian English. History, Functions, and Features. Ed. by Zoya G. Proshina and Anna A. Eddy. Cambridge University Press.2016. 309 p.

20. Schneider Ed.W. English Around the World. Cambridge University Press, 2011. 280 p.

21. Seidlhofer B. Understanding English as a Lingua Franca. Oxford Applied Linguistics. Oxford University Press, 2013. p. 240.

22. Velichkovsky V.V. Open Access Publishing - a Challenge for Russian Psychology// Psychology Science Quarterly.2009, № 51, p. 147-159.

Поступила в редакцию 25.02.2020 г. Принята к публикации 04.03.2020 г.

Для циитирования:

Иванова Н.К. Английский язык в российской научной среде: основные тенденции и особенности функционирования и восприятия // Вестник Гуманитарного института. 2020. № 1. C. 85-95. URL: https://isuct-bhi.ru/sites/default/files/issue/2020/1/bhi-2020-1085.pdf 